\title{
Implementação de um programa de mestrado acadêmico voltado ao processo do envelhecimento
}

\section{Implementation of an academic master's program oriented to the aging process}

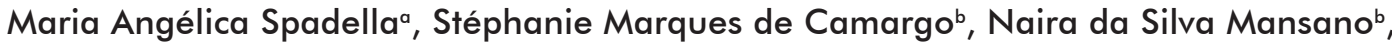 \\ Carlos Alberto Lazarinic, Spencer Luiz Marques Payãod, Marcos Renato de Assise, \\ Paulo Marcondes Carvalho-Juniorf, Agnaldo Bruno Chies ${ }^{*}$
}

a Bióloga, Doutora em Biologia Celular e Estrutural, Docente Permanente do Programa de Mestrado Acadêmico em Saúde e Envelhecimento da Faculdade de Medicina de Marília, Famema, Marília, São Paulo. <maspadella@gmail.com>

b Enfermeiras, Discentes do Programa de Mestrado Acadêmico em Saúde e Envelhecimento da Faculdade de Medicina de Marília, Famema, Marília, São Paulo. <stephanie-camargo@hotmail.com><naira.mansano@gmail.com>

Farmacêutico, Doutor em Farmacologia, Docente Permanente do Programa de Mestrado Acadêmico em Saúde e Envelhecimento da Faculdade de Medicina de Marília, Famema, Marília, São Paulo. <lazarini@famema.br>

d Biólogo, Livre docente em Genética Humana e Médica pela UNIFESP/EPM, Docente Permanente do Programa de Mestrado Acadêmico em Saúde e Envelhecimento e Diretor de Pós-graduação, Pesquisa e Extensão da Faculdade de Medicina de Marília, Famema, Marília, São Paulo. <slmpayao@famema.br>

- Médico reumatologista e fisiatra, Doutor em Reabilitação, Vice-coordenador do Programa de Mestrado Acadêmico em Saúde e Envelhecimento da Faculdade de Medicina de Marília, Famema, Marília, São Paulo. <a.assismr@gmail.com>

Médico, Doutor em Engenharia Biomédica, Docente Permanente do Programa de Mestrado Acadêmico em Saúde e Envelhecimento da Faculdade de Medicina de Marília, Famema, Marília, São Paulo._marcondes.paulo@gmail.com>

- Farmacêutico, Doutor em Farmacologia, Coordenador do Programa de Mestrado Acadêmico em Saúde e Envelhecimento da Faculdade de Medicina de Marília, Famema, Marília, São Paulo. <agnaldochies@hotmail.com>

\section{ARTICLE INFO}

\section{Article history}

Received: 27/04/2015

Accepted: $11 / 05 / 2015$

\section{Correspondent Author}

Agnaldo Bruno Chies

Av: Monte Carmelo, 800 - Fragata

17519-030 Marília, SP, Brasil

<agnaldochies@hotmail.com>

(C) 2014 All rights reserved

\section{Editors}

Alfredo Cataldo Neto

Irenio Gomes

\begin{abstract}
RESUMO
Objetivo: Relatar estratégias de avaliação em processo de implementação do programa e ajustes que foram feitos visando o aprimoramento do mesmo. Métodos: Relato de experiência, sustentado em análise documental. Os dados são provenientes de registros da Apresentação de Propostas de Cursos Novos; atas de reuniões do Conselho e do corpo docente do Mestrado Acadêmico; registros e documentos da Secretaria de Pós-graduação; editais dos processos seletivos; documentos das bancas de qualificação e defesa; publicações em eventos e periódicos científicos; relatórios da I e II Oficina de Avaliação do Programa; relatórios para o sistema Coleta de Dados da CAPES e relatório de avaliação da CAPES. Os documentos compreendem o período de 2011 a 2014 . Resultados: Com base na análise dos documentos foi possível relatar as principais estratégias visando estabelecer um plano de gestão para superação das fragilidades apontadas, bem como para a consolidação das fortalezas, com destaque para a reestruturação da matriz curricular e do processo seletivo, além da elaboração do manual do estudante com informações sobre o Programa. Conclusões: As reformas implementadas, a partir de um processo contínuo de avaliação, trouxeram avanços importantes na estruturação do Programa, tendo em vista a interdisciplinaridade e a área de concentração em Saúde e Envelhecimento.
\end{abstract}

DesCRITORES: Educação de Pós-Graduação; Envelhecimento; Avaliação Educacional; Avaliação de Programas e Projetos de Saúde.

\begin{abstract}
Objective: Report strategies to evaluate the process or program implementation and following adjustments that were made in order to improve it. Methods: Report of an experience, supported by documentary analysis. Data comes from: records of the Presentation of New Courses Proposals; meetings minutes of the Council and the faculty members meeting; records and documents of the Postgraduate Department secretary; edicts of recruitment processes; documents of qualification and defense committees; publications in scientific journals and events; reports of the First and Second Program Evaluation Workshop; reports of the CAPES' data system of and CAPES evaluation report. The documents cover the period 201 1-2014. Results: Based on the analysis of the documents was possible to report the key strategies to establish a management plan for overcoming the identified weaknesses, as well as the strengths consolidation, with emphasis on the restructuring the curriculum and the students' applications selection process, in addition to the preparation of the student syllabus with information about the Program. Conclusions: The implemented reforms as from a continuous process of evaluation have brought important advances in structuring the Program, towards interdisciplinarity and the concentration area of Health and Aging.

KeYwords: Education, Graduate; Aging; Educational Measurement; Program Evaluation.
\end{abstract}

\footnotetext{
* Contribuição dos autores: Agnaldo Bruno Chies e Maria Angélica Spadella, coordenação dos trabalhos; todos os autores fizeram levantamento/análise dos dados e elaboração do texto; Maria Angélica Spadella, Paulo Marcondes Carvalho-Junior e Stéphanie Marques de Camargo, formatação do texto.
} 


\section{INTRODUÇÃO}

A Faculdade de Medicina de Marília (Famema), criada em 19 de janeiro de 1966, oferece atualmente os cursos de Medicina e Enfermagem. Desde a sua fundação, a Famema buscou implantar sua PósGraduação Stricto sensu. Este objetivo foi alcançado com a recomendação dos Programas de Mestrado, em Ensino em Saúde (2010 - Profissional) e em Saúde e Envelhecimento (2011 - Acadêmico), pela Coordenação de Aperfeiçoamento de Pessoal de Nível Superior (CAPES). Estes Programas foram propostos à Área Interdisciplinar da CAPES, uma vez que a Famema tem um rico histórico interdisciplinar no ensino, construído ao longo de sua história. De fato, a Famema implementou uma profunda reforma curricular nos cursos de Medicina (em 1997) e de Enfermagem (em 1998) e, por conta disso, passou a empregar métodos ativos de ensino aprendizagem que têm como um dos fundamentos a interdisciplinaridade $\mathrm{e}^{1,2,3}$.

Para a estruturação da "Apresentação de Propostas de Cursos Novos" (APCN) do Programa de Mestrado Acadêmico, associaram-se docentes da Famema que tinham experiência no cuidado ao idoso ou que estudavam doenças crônico-degenerativas, bem como processos fisiopatológicos relacionados ao envelhecimento e com comprovada produção científica. Agregaram-se a este grupo, docentes com experiência nos processos educacionais e no desenvolvimento de tecnologias de organização de serviços de saúde e de formação de profissionais para atuarem nestes serviços. Assim, o corpo docente proposto na APCN, de caráter multidisciplinar, foi composto por oito médicos, três biólogos, três enfermeiros, dois farmacêuticos e um biomédico.

A área de concentração proposta foi "Biologia e Envelhecimento" uma vez que o cuidado com a saúde no envelhecer é um grande desafio para a sociedade moderna, sobretudo nos países onde a pirâmide etária está se invertendo. Este fenômeno já ocorre no Brasil ${ }^{4}$, inclusive na região de Marília/SP. Assim, entendemos que o Programa proposto atende a uma demanda local e regional, uma vez que o município de Marília é de médio porte, exercendo a função de polo formador na região sudoeste do estado de São Paulo. O Programa proposto, contudo, não é voltado à geriatria ou gerontologia, mas ao "processo do envelhecimento".

Assim, o objetivo do Programa e o perfil do egresso contemplam ${ }^{5}$, respectivamente:

"Formar massa crítica de qualidade para a docência e pesquisa voltada aos processos biológicos, epidemiológicos e sociais envolvidos na manutenção da saúde e no desenvolvimento das doenças, nas diversas etapas do ciclo da vida, com foco no processo do envelhecimento."
"Busca-se, assim, formar profissionais críticos, reflexivos, com ampla visão do ciclo da vida desde o nascimento até o envelhecimento e, cientificamente preparados para compreender os processos biológicos, epidemiológicos e sociais que determinam saúde/doença no envelhecer, com vistas ao aprimoramento do cuidado do indivíduo neste processo. Pretende-se ainda a formação de um mestre capaz de trabalhar em equipe multiprofissional/ interdisciplinar e que esteja apto a formar estudantes de graduação com esta visão de trabalho em equipe, sabendo utilizar o método científico. Por fim, espera-se que o egresso deste programa de pós-graduação também tenha a competência para estruturar projetos de pesquisa relevantes, metodologicamente bem estruturados e exequiveis."

$\mathrm{Na} \mathrm{APCN}^{5}$, três linhas de pesquisa do Programa foram definidas, conforme se segue:

1. Gestão e educação em saúde com ênfase em métodos ativos de ensino-aprendizagem;

2. Organização morfofuncional e homeostasia nas diferentes fases do ciclo da vida;

3. Aspectos biológicos, epidemiológicos e sociais relacionados ao envelhecimento e às doenças associadas.

Uma vez tendo seu funcionamento autorizado pela CAPES, a implementação deste Programa de Pós-Graduação passou a ser o maior desafio. Assim, o objetivo do presente estudo é relatar as estratégias de avaliação em processo e os ajustes que foram feitos visando o aprimoramento do Programa.

\section{MÉTODOS}

Este trabalho relata as estratégias para implementação do Programa de Mestrado Acadêmico em Saúde e Envelhecimento (PMASE) da Famema, sustentado em análise documental, com discussões sobre os desafios e as ações para sua consolidação.

Os dados obtidos são provenientes das seguintes fontes:

a) APCN submetida a CAPES em 2011;

b) Atas de reuniões do Conselho e do corpo docente do Mestrado Acadêmico;

c) Registros e documentos da Secretaria de Pósgraduação;

d) Editais dos processos seletivos de 2011 a 2014;

e) Documentos das bancas de qualificação e defesa;

f) Publicações em eventos e periódicos científicos;

g) Relatórios do I e II Fórum de Avaliação do PMASE;

h) Relatórios para o sistema Coleta de Dados da CAPES dos anos de 2013 e 2014;

i) Relatório de avaliação da CAPES referente ao triênio 2010-2012. 
Este trabalho está de acordo com as normas e diretrizes regulamentadoras de pesquisa envolvendo seres humanos conforme a Resolução 466/12 do Conselho Nacional de Saúde, e foi submetido ao Comitê de Ética em Pesquisa Envolvendo Seres Humanos da Famema.

\section{RESULTADOS E DISCUSSÃO}

\section{Demanda do Programa}

Desde o $1^{\circ}$ processo seletivo em 2011, o Programa teve procura média de dois candidatos por vaga. De 2011 a 2014, 126 candidatos se inscreveram no processo seletivo e, destes, 61 (48,4\%) foram aprovados. Dentre os aprovados, predominam egressos de cursos de graduação da área da saúde, sobretudo enfermeiros e médicos (Figura 1). Este perfil é esperado, pois a área de concentração do Programa é voltada ao envelhecimento. Fato semelhante ocorreu com os Programas: Biodiversidade Tropical da região norte do país, procurado predominantemente por profissionais da área de Ciências Biológicas ${ }^{6}$ e, Ciência da Informação da região nordeste, procurado por profissionais da área de Informática ${ }^{7}$. Esta diversidade profissional é benéfica, considerando que o Mestrado Acadêmico da Famema busca formar mestres capazes de exercer trabalho multiprofissional/interdisciplinar ${ }^{5}$.

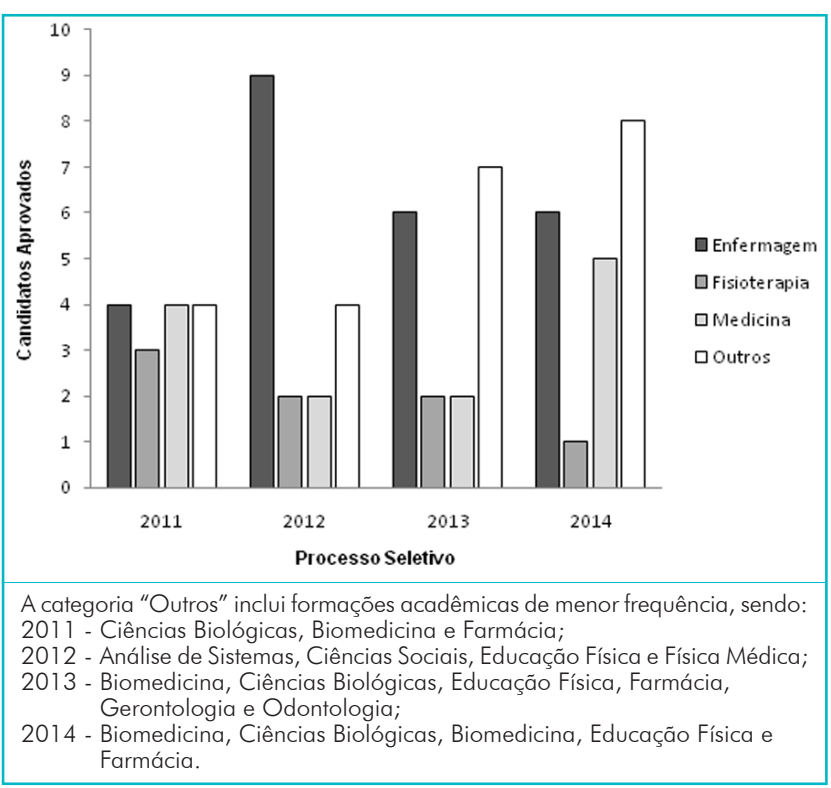

Figura 1. Formação acadêmica dos aprovados nos processos seletivos de 2011 a 2014 para o Mestrado Acadêmico da Famema.

\section{Avaliação do Programa em processo}

Desde o início, o Mestrado Acadêmico da Famema, tem mobilizado esforços para sua implementação e consolidação. Sempre houve a preocupação de identificar o que precisa ser corrigido ou modificado, visando a formação dos estudantes nos moldes exigidos pela área Interdisciplinar da CAPES. Neste sentido, as fragilidades apontadas na análise da APCN feita pela CAPES em 2011 e na avaliação trienal de 2013 foram consideradas. Para os direcionamentos necessários também foram importantes as informações e troca de experiências nas Reuniões de Coordenadores de Programas Interdisciplinares da CAPES (ReCoPI).

O primeiro ajuste necessário foi a alteração do nome para Programa de Mestrado Acadêmico em Saúde e Envelhecimento (PMASE). Esta modificação deveu-se ao fato dos projetos desenvolvidos no Programa serem mais relacionados à área da saúde e ao processo do envelhecimento. Saúde e Envelhecimento também reflete melhor o perfil dos egressos.

O PMASE também tem sido regularmente avaliado pelos pós-graduandos e docentes por meio dos "Fóruns de Avaliação dos Programas de Pós-graduação Stricto sensu da Famema" ${ }^{8,9}$. Nestes Fóruns discute-se em grupo os seguintes eixos norteadores: Organização curricular/disciplinas, Relação orientando-orientador/ andamento dos projetos e Organização do Programa/ Regimento. Nestas discussões, visa-se identificar fragilidades e fortalezas do Programa, além de discutir e socializar informações. Os principais pontos levantados são apresentados e discutidos em plenária, sendo evidenciados na Figura 2.

Com base nesses resultados estabeleceu-se um plano de gestão para superação das fragilidades apontadas, bem como para consolidação das fortalezas. Como a proposta do presente trabalho é relatar os ajustes feitos para aprimoramento do Programa, as fragilidades levantadas e as ações para superá-las são o foco da discussão. Cabe ressaltar que, para atender às demandas de docentes e discentes, reestruturações já foram feitas e alguns avanços já são reais.

\section{Ações para correção das fragilidades}

A matriz curricular proposta na $\mathrm{APCN}^{5}$ e, cursada pelas I e II turmas do PMASE foi considerada como um ponto a ser revisto. Em 2011, a própria área Interdisciplinar da CAPES apontava que as disciplinas obrigatórias eram estanques e pouco integradas entre si, além de desarticuladas das linhas de pesquisa do Programa. $O$ fato de estas disciplinas serem ministradas por apenas um professor implicava em menor possibilidade de interação do corpo docente. Além disso, no I Fórum de Avaliação do curso ${ }^{8}$, docentes e discentes relataram que as disciplinas obrigatórias aprofundavam o conteúdo cognitivo, mas não asseguravam que todos discentes tivessem aproveitamento adequado. Isto 


\begin{tabular}{|c|c|}
\hline Fortalezas & Fragilidades \\
\hline - Histórico Institucional de docência multidisciplinar & - Matriz curricular pouco interdisciplinar \\
\hline - Apoio Institucional ao Programa & - Número excessivo de créditos \\
\hline $\begin{array}{l}\text { - Agregação de docentes e discentes no desenvolvimento de projetos } \\
\text { voltados às necessidades da comunidade }\end{array}$ & - Melhor definição das atividades acadêmicas científicas complementares \\
\hline $\begin{array}{l}\text { - Docentes com disponibilidade de horários para reuniões e trabalhos em } \\
\text { conjunto }\end{array}$ & - Necessidade de elaboração de um Manual do Estudante \\
\hline - Maioria dos docentes com infraestrutura para pesquisa já estabelecida & - Pouca divulgação do processo seletivo \\
\hline $\begin{array}{l}\text { - Experiência de vários docentes na obtenção de recursos junto às agências } \\
\text { de fomento }\end{array}$ & $\begin{array}{l}\text { - Pouca aproximação dos ingressantes no Programa com a linha de pesquisa } \\
\text { do orientador }\end{array}$ \\
\hline - Parcerias e intercâmbios com outras Instituições de ensino/pesquisa & $\begin{array}{l}\text { - Acolhimento inadequado dos docentes aos candidatos interessados por } \\
\text { vaga no Programa }\end{array}$ \\
\hline - Produtividade crescente dos docentes nos últimos anos & $\begin{array}{l}\text { - Projetos pouco interdisciplinares e não completamente relacionados à área } \\
\text { de concentração do Programa }\end{array}$ \\
\hline - Boa demanda de procura de candidatos por vaga no Programa & - Incipiente experiência docente em orientar na pós-graduação \\
\hline • Mínima evasão discente & - Poucas bolsas de demanda social disponíveis \\
\hline - Defesa da dissertação dentro do prazo de 24 meses & - Descontínua participação discente nas reuniões do Conselho do Programa \\
\hline - Publicação de artigos científicos derivados das dissertações & - Falha no fluxo de informação do Programa \\
\hline $\begin{array}{l}\text { - Consulta periódica aos egressos para acompanhar sua inserção e/ou } \\
\text { crescimento profissional }\end{array}$ & - Organização deficiente da secretaria do Programa \\
\hline \multicolumn{2}{|l|}{ - Realização de oficinas de avaliação do Programa } \\
\hline $\begin{array}{l}\text { - Disposição de docentes e discentes para avaliar o Programa e corrigir } \\
\text { fragilidades }\end{array}$ & \\
\hline
\end{tabular}

Figura 2. Consolidado dos Fóruns de Avaliação do Programa de Mestrado Acadêmico em Saúde e Envelhecimento realizados nos anos de 2013 e 2014.

ficou evidente para os estudantes que não tiveram estes conteúdos durante a graduação. A forma de organização das disciplinas obrigatórias também comprometia a interdisciplinaridade do Programa, uma vez que não propiciava a integração de discentes/ docentes que desenvolviam projetos de pesquisa de naturezas distintas. Por conta desta organização, a grade curricular ficou conteudista e com número excessivo de créditos. Consequentemente, ao invés de empenharem tempo em um trabalho cooperativo e criativo, os pós-graduandos desdobravam-se para cumprir uma carga horária extensa. As mesmas fragilidades foram apontadas quanto às disciplinas optativas.

Após discussão cuidadosa no Conselho do PMASE, contando inclusive com opiniões de docentes com experiência acumulada em outros programas da área Interdisciplinar da CAPES, chegou-se à conclusão da necessidade de profunda reestruturação da matriz curricular. Assim, com base nas avaliações, a matriz curricular foi amplamente reformulada, visando maior contexto interdisciplinar, aprendizado e aproveitamento dos conteúdos pelos pós-graduandos e redução do número de créditos. A grade curricular atual do Programa, com vigência desde $2014^{10,11}$, abrange cinco disciplinas obrigatórias e sete optativas. As Figuras 3 e 4 mostram comparativamente as grades curriculares de 2012 e de 2014. Nesta reestruturação disciplinas que tinham objetivos de aprendizagem similares foram integradas, tornando-se mais interdisciplinares, com envolvimento de vários docentes e, voltadas ao processo do envelhecimento.

A matriz curricular antiga previa o cumprimento de 82 créditos, um número que se mostrou excessivo. Com a reformulação, reduziu-se o número de créditos cumpridos por meio de disciplinas, possibilitando ao discente desenvolver outras atividades, também importantes para sua formação. Dessa maneira, na grade curricular atual, o pós-graduando deve cumprir 18 créditos em disciplinas obrigatórias e quatro créditos em disciplinas optativas, o que significa uma redução de 18 créditos em disciplinas (Figuras de 3 a 5). As atividades didáticas obrigatórias também tiveram redução de 10 para dois créditos e foram integradas à disciplina obrigatória "Metodologias de Ensino-aprendizagem em Saúde”, para o melhor acompanhamento dos pósgraduandos. Foram previstos também dois créditos em atividades acadêmicas científicas complementares, as quais propiciam aos estudantes vivências pedagógicas ou técnico-científicas não previstas na matriz curricular do Programa, mas que são de interesse para sua formação. Além disso, 24 créditos foram atribuídos à elaboração da dissertação e envio à publicação do artigo científico relacionado à dissertação ${ }^{10,11}$. Assim, atualmente os estudantes devem cumprir no mínimo 50 créditos para a conclusão do curso, um número que tem se mostrado mais adequado. 


\begin{tabular}{|c|c|c|c|}
\hline \multicolumn{4}{|c|}{ Grade de Disciplinas Obrigatórias } \\
\hline 2012 & CR & 2014 & CR \\
\hline Bioética & \multirow{4}{*}{4} & \multirow{4}{*}{ Bases da metodologia de pesquisa científica aplicada à saúde } & \multirow{4}{*}{6} \\
\hline Epidemiologia clínica e medicina baseada em evidências & & & \\
\hline Princípios básicos de estatística para a área da saúde & & & \\
\hline Elaboração e desenvolvimento de projetos de pesquisa & & & \\
\hline Métodos ativos de ensino-aprendizagem em saúde & 4 & Metodologias de ensino-aprendizagem em saúde & 4 \\
\hline Cuidado em saúde & 4 & $\begin{array}{l}\text { Cuidado interdisciplinar ao individuo no processo de } \\
\text { envelhecimento }\end{array}$ & 4 \\
\hline Genética e epidemiologia do envelhecimento & 4 & $\begin{array}{l}\text { Aspectos genéticos, epidemiológicos e sociais do } \\
\text { envelhecimento }\end{array}$ & 2 \\
\hline Seminários da Pós-graduação da Famema & 4 & Seminários & 2 \\
\hline Total & 32 & Total & 18 \\
\hline
\end{tabular}

Figura 3. Grade de disciplinas obrigatórias do Programa de Mestrado Acadêmico em Saúde e Envelhecimento, comparando a proposta anterior (2012) com a atual (2014).

\begin{tabular}{|c|c|c|c|}
\hline \multicolumn{4}{|c|}{ Grade de Disciplinas Optativas } \\
\hline 2012 & CR & 2014 & CR \\
\hline Noções fundamentais em microscopia de luz & \multirow{3}{*}{4} & \multirow{3}{*}{$\begin{array}{l}\text { Técnicas laboratoriais empregadas na investigação de processos } \\
\text { fisiopatológicos relacionados ao envelhecimento }\end{array}$} & \multirow{3}{*}{4} \\
\hline Biologia molecular aplicada: da teoria à prática & & & \\
\hline Implicações do uso terapêutico de células-tronco & & & \\
\hline Atividade física nas doenças crônicas não transmissíveis & \multirow{3}{*}{4} & \multirow{3}{*}{ Atividade física e saúde } & \multirow{3}{*}{2} \\
\hline Endotélio e exercício físico & & & \\
\hline Envelhecimento, alterações metabólicas e função cardíaca & & & \\
\hline Bases fisiopatológicas dos processos imunoalérgicos & 4 & Envelhecimento e imunidade & 2 \\
\hline Humanização do cuidado em saúde & \multirow{2}{*}{4} & \multirow{2}{*}{ Integralidade e humanização do cuidado } & \multirow{2}{*}{4} \\
\hline Avaliação em saúde & & & \\
\hline Ensaios Clínicos* & 4 & Bioestatística*** & 4 \\
\hline \multirow{2}{*}{ Embriogênese e morfologia do sistema genital masculino** } & \multirow{2}{*}{4} & Coleta e análise de dados em pesquisa qualitativa ${ }^{\#}$ & 7 \\
\hline & & Avanços em métodos ativos de ensino-aprendizagem em Saúde ${ }^{\#}$ & 2 \\
\hline Total & 44 & Total & 25 \\
\hline
\end{tabular}

Figura 4. Grade de disciplinas optativas do Programa de Mestrado Acadêmico em Saúde e Envelhecimento, comparando a proposta anterior (2012) com a atual (2014).

\begin{tabular}{|c|c|c|}
\hline \multirow[b]{2}{*}{ Quesito } & \multirow[b]{2}{*}{$\mathbf{C R}$} & Detalhamento \\
\hline & & 2012 \\
\hline $\begin{array}{l}\text { Disciplinas/ } \\
\text { Outras atividades }\end{array}$ & 60 & $\begin{array}{l}32 \text { em disciplinas obrigatórias } \\
8 \text { em disciplinas optativas } \\
20 \text { créditos em outras atividades, sendo: } \\
10 \text { créditos em atividade(s) didática(s) obrigatória(s), } \\
10 \text { créditos em atividades didáticas, ambulatoriais e/ou laboratoriais }\end{array}$ \\
\hline Dissertação & 22 & Elaboração da dissertação e submissão à revista indexada do artigo científico derivado da dissertação \\
\hline Total & 82 & \\
\hline Quesito & CR & 2014 \\
\hline $\begin{array}{l}\text { Disciplinas/ } \\
\text { Outras atividades }\end{array}$ & 26 & $\begin{array}{l}18 \text { em disciplinas obrigatórias } \\
4 \text { em disciplinas optativas } \\
4 \text { créditos em outras atividades, sendo: } \\
2 \text { créditos em atividade(s) didática(s) obrigatória(s), } \\
2 \text { créditos em atividades didáticas científicas complementares }\end{array}$ \\
\hline Dissertação & 24 & Elaboração da dissertação e submissão à revista indexada do artigo científico derivado da dissertação \\
\hline Total & 50 & \\
\hline
\end{tabular}

Figura 5. Número de créditos do Programa de Mestrado Acadêmico em Saúde e Envelhecimento preconizados em 2012 (anterior) e em 2014 (vigente). 
Outro aspecto levantado foi a necessidade de estruturação de um manual do estudante, contemplando orientações para auxiliar o pós-graduando no percurso do mestrado. A elaboração deste manual baseou-se nas sugestões dadas pelos discentes e docentes nos Fóruns de Avaliação ${ }^{8,9}$. Procurou-se sistematizar informações sobre: grade de disciplinas obrigatórias e optativas e calendário de oferecimento, número de créditos exigidos, datas limite para o exame de qualificação e defesa, critérios para concessão de bolsas de demanda social, entre outras. A apresentação do Manual do Estudante ocorreu em Março de 2015, na aula inaugural da IV turma do Mestrado Acadêmico e, os ganhos com sua introdução já são visíveis, pois permitiu a organização da estrutura acadêmica do Programa.

Outra demanda levantada referia-se ao processo seletivo. Percebeu-se a necessidade de articular a área de conhecimento dos candidatos ao curso com a linha de pesquisa do potencial orientador ${ }^{10}$. Assim, desde 2013, a seleção passou a ser direcionada à vaga do orientador permitiram ao candidato identificar o orientador que atenda aos seus interesses acadêmico e profissional e vice-versa. Além disso, o contato candidato-orientador antes do processo seletivo passou a ser obrigatório. Com isso, os docentes passaram a conhecer precocemente seus candidatos para o estabelecimento de vínculo. Outro ponto levantado foi a pouca divulgação do processo seletivo. Assim, além do envio de cartazes e mensagens eletrônicas e, publicação em redes sociais, esta divulgação passou a ser feita pessoalmente por meio de visitas às Instituições de ensino e pesquisa/ Instituições de saúde e afins, envolvendo, inclusive, os pós-graduandos neste trabalho.

Também foi levantada a necessidade de ações visando melhorar a interdisciplinaridade dos projetos e a articulação destes com a área de concentração do Programa. Isto porque o corpo docente do Programa atua e pesquisa temas que de alguma forma relacionamse ao envelhecimento; contudo, o processo do envelhecer deve ser fortalecido na elaboração dos projetos. A reforma da matriz curricular trouxe avanços na construção de projetos mais interdisciplinares, fortalecendo também a área de concentração. Além disso, outras iniciativas como o incentivo ao desenvolvimento de projetos em parcerias (dentro e fora do Programa) e a discussão dos projetos em seminários da Pós-graduação tem contribuído neste processo. A solicitação de pareceres para os projetos dos pós-graduandos a assessores ad hoc, pertencentes a programas de pós-graduação com mais experiência no envelhecimento, integrantes da Rede de Programas Interdisciplinares do Envelhecimento (REPRINTE) foi outra estratégia válida.
Ainda, buscando meios de promover a interdisciplinaridade, realizou-se uma oficina em setembro de 2014, com a participação dos docentes permanentes do Programa, objetivando a identificação de "problemas complexos" a serem explorados pelos futuros pósgraduandos.

Com o andamento do curso, o corpo docente do Programa vem acumulando experiência em orientação. Isto se constata pelo cumprimento dos prazos, por publicações de artigos científicos relacionados às dissertações e pelas parcerias e intercâmbios com outras Instituições de ensino/pesquisa ${ }^{10,11}$. Em relação a este último aspecto, três discentes do PMASE foram contemplados com cotas de bolsa Fórmula Santander, as quais possibilitaram a inserção destes discentes em instituições internacionais de ensino superior, favorecendo futuros intercâmbios, que são fundamentais para o crescimento do Programa. O Programa foi também contemplado pela CAPES com uma cota de bolsa de pós-doutorado, o que aprimora a experiência de orientação do corpo docente na pósgraduação, inclusive em níveis mais complexos.

Em 2012, o PMASE contava com três cotas de bolsa de Demanda Social (DS) da CAPES e, em 2014, passou a contar com mais duas. A concessão destas cinco bolsas tem sido feita por mérito, ou seja, de acordo com a classificação do discente no processo seletivo por meio do qual ele ingressou no Programa. O Conselho entende que esse critério de concessão é mais justo, pois leva em consideração o desempenho individual do ingressante sem outras interferências. A ampliação do número de bolsas continua sendo uma prioridade do Programa, pois alunos que recebem bolsas tendem a ser mais produtivos, uma vez que podem frequentar o curso em regime de dedicação integral e exclusiva.

A representação discente nas reuniões do Conselho foi descontínua durante o ano de 2014, devido à falha na convocação do mesmo. Isto comprometeu a comunicação entre o Programa e os pós-graduandos. Neste sentido, o Conselho, desde o início de 2015, vem esclarecendo o papel da representação discente, bem como sistematizando sua participação nas reuniões quando cabível.

Quanto ao fluxo de informações, docentes e discentes identificam falhas, sobretudo em relação à comunicação entre o Conselho do Programa e o corpo discente. Isto ficou evidente no processo de distribuição de bolsas, ocorrido em 2014, que causou descontentamento entre os pós-graduandos. Contribuiu para superar esta fragilidade, a elaboração do Manual do Estudante. Esforços também estão sendo feitos para melhorar o processo de trabalho da secretaria, no que 
diz respeito à organização dos arquivos e a divulgação de informações aos docentes e pós-graduandos.

\section{Consolidação das fortalezas e planejamento}

Por ser uma Instituição pequena, a Famema enfrenta muitos desafios, mas a pós-graduação é encarada como prioritária e, como tal, recebe apoio necessário ao seu adequado funcionamento. $O$ apoio Institucional é reconhecido pelos docentes e discentes e se traduz em disponibilização de carga horária aos docentes do Programa, infraestrutura destinada à pós-graduação (salas de aulas, equipamentos, manutenção dos laboratórios, etc.) e recursos humanos ${ }^{10,11}$. O Programa também estimula a busca por recursos externos para pesquisa, a fim de garantir sua sobrevivência. Por exemplo, a montagem do laboratório interdisciplinar voltado à pesquisa do estresse oxidativo foi concretizada graças ao trabalho de alguns docentes do Programa que buscaram recursos junto à Fundação de Amparo à Pesquisa do Estado de São Paulo (FAPESP).

A experiência de trabalho multidisciplinar da Famema na graduação, conquistada com a reforma curricular ${ }^{2,3}$, tem sido importante para a implementação deste programa interdisciplinar de Pós-Graduação. Neste sentido, docentes e discentes do Programa se empenham na construção de projetos interdisciplinares, saindo do que chamamos de "zona de conforto", buscando parcerias para propor pesquisas que atendam melhor às demandas da sociedade. Obviamente, este é um caminho árduo e cheio de obstáculos. Não raramente ocorrem dificuldades metodológicas, interpessoais ou logísticas, sendo necessárias mudanças de rumo. Porém, tem-se a convicção que a disposição em fazer "algo diferente" é uma importante fortaleza.

O PMASE também tem se esmerado em cumprir o prazo máximo de 24 meses para a defesa da dissertação de mestrado, conforme consta no Regimento do Programa. De fato, dos 16 pós-graduandos da primeira turma, 14 defenderam dentro do prazo, apenas um defendeu com dois meses de atraso e um trancou matrícula por licença médica. Das 15 dissertações defendidas por essa turma, sete já tiveram seus principais resultados publicados em revistas de boa qualidade, cuja classificação no Qualis CAPES, da área Interdisciplinar, abrange: A1 e $\mathrm{A} 2=14,3 \%$ cada; $\mathrm{B} 1=42,9 \%$ e $\mathrm{B} 2=28,6 \%$. Estes resultados são coerentes com dados da literatura ${ }^{12}$.

Em consulta aos egressos da primeira turma, tivemos a informação de que o título obtido no PMASE foi fundamental para a contratação de dois egressos em Instituições de Ensino Superior da região de Marília/ SP. Outros pós-graduandos, que já eram docentes, reconheceram-se mais qualificados para exercerem suas atividades docentes após terem conquistado a titulação. Além disso, ao menos quatro destes egressos estão em contato direto com estudantes de Iniciação Científica, o que reflete a capacidade destes em formar outros estudantes.

Todavia, pelo fato do Programa não oferecer ainda o doutorado, não se pode dizer que a formação dos egressos está concluída. Por conta disso, estes são estimulados a ingressarem no doutorado de outros programas de pós-graduação. Até o final de 2014, quatro egressos já haviam efetivado suas matrículas em programas de doutorado e outro estava aguardando abertura de processo seletivo.

Por fim, embora diversas fragilidades tenham sido superadas ou estejam em processo de correção, sabe-se que o PMASE requer tempo para corrigir deficiências mais complexas, a fim de articular-se com outros programas de pós-graduação no cenário nacional e internacional, sobretudo aqueles interdisciplinares voltados ao processo do envelhecimento. Tratase de um Programa recém-criado, pioneiro em uma Instituição pequena e com poucos recursos humanos e financeiros. Porém, apesar destas adversidades, o PMASE tem um grande potencial de crescimento, pois conta com motivação e disposição de todos os envolvidos na sua construção (discentes, docentes e gestores) para corrigir suas fragilidades e consolidar suas fortalezas.

\section{AGRADECIMENTOS}

Agradecemos aos colaboradores Amauri Aparecido Theatro, Cristielle Azevedo Santos e Fabrício Martinezzi Beazim pelo suporte logístico na recuperação de informações para a elaboração deste artigo.

\section{REFERÊNCIAS}

1. Gomes R, Francisco AM, Tonhom SF da R, Costa MCG da, Hamamoto CG, Pinheiro OL, et al. A formação médica ancorada na aprendizagem baseada em problema: uma avaliação qualitativa. Interface - Comunicação, Saúde, Educação. março de 2009;13(28):71-83.

2. Faculdade de Medicina de Marília. Projeto Pedagógico do Curso de Medicina [Internet]. 2014 [citado 27 de abril de 2015]. Recuperado de: http://www.famema.br/ensino/cursos/ docs/protocolo43158_PPC\%20Medicina.pdf

3. Faculdade de Medicina de Marília. Projeto pedagógico do Curso de Enfermagem [Internet]. 2008 [citado 27 de abril de 2015]. Recuperado de: http://www.famema.br/ensino/cursos/ docs/PPC\%20Enfermagem\%20final.pdf

4. Vasconcelos Ana Maria Nogales, Gomes Marília Miranda Forte. Transição demográfica: a experiência brasileira. Epidemiol. Serv. Saúde [periódico na Internet]. 2012 Dez [citado 2015 Abr 27]; 21(4): 539-548. Disponível em: http:/ scielo.iec.pa.gov.br/scielo.php?script $=$ sci_arttext $\&$ pid $=$ S1679. 49742012000400003\&lng=pt. http://dx.doi.org/10.5123/ S1679-49742012000400003. 
5. Faculdade de Medicina de Marília. Apresentação de Propostas de Cursos Novos - APCN [Internet]. 2011 [citado 27 de abril de 2015]. Recuperado de: https://sucupira.capes. gov.br/sucupira/public/proposta/index_propostas.jsf

6. Cunha HFA, Cunha AC da, Silva JMC da. A PósGraduação Stricto sensu em Biodiversidade Tropical no Amapá: uma experiência em construção. RBPG. março de 2013;10(19):213-37.

7. Figueiredo HA, Morais LEM, Ramalho FA. Busca da informação para qualificação: um estudo com candidatos ao mestrado em ciência da informação do Programa de PósGraduação em Ciência da Informação - UFPB | Figueiredo | Informação \& Sociedade: Estudos. Informação \& Sociedade: Estudos. 2013;23(2):99-111.
8. Faculdade de Medicina de Marília. Relatório I Fórum de Avaliação dos Programas de Pós-Graduação. 2013.

9. Faculdade de Medicina de Marília. Relatório II Fórum de Avaliação dos Programas de Pós-Graduação. 2014.

10. Faculdade de Medicina de Marília. Relatório para o Sistema COLETA-2013. 2013.

11. Faculdade de Medicina de Marília. Relatório para o Sistema COLETA-2014. 2014.

12. Erdmann AL, Marziale MHP, Pedreira M da LG, Lana FCF, Pagliuca LMF, Padilha MI, et al. A avaliação de periódicos científicos qualis e a produção brasileira de artigos da área de enfermagem. Revista Latino-Americana de Enfermagem. 2009;17:403-9. 